\title{
Low levels of cardiovascular risk factors and coronary heart disease in a UK Chinese population
}

Jane O Harland, Nigel Unwin, Raj S Bhopal, Martin White, Bill Watson, Mike Laker, K G M M Alberti

\begin{abstract}
Objective-To compare the prevalence of cardiovascular risk factors and coronary heart disease in Chinese and Europid adults.

Design-Population based, cross sectional
\end{abstract} survey.

Setting-Newcastle upon Tyne, UK, 199193.

Subjects-Altogether 380 Chinese and 625 Europid adults, aged 25-64 years.

Main outcome measures-Fasting lipid levels, blood pressure, body mass index (BMI), the proportions who smoked, and the prevalence of coronary heart disease based on the Rose angina questionnaire and major electrocardiographic abnormalities on resting 12 lead electrocardiogram (Minnesota codes 1.1-1.2). All figures were age adjusted to the 1991 England and Wales population.

Medicine, University of Newcastle

$\mathrm{J} O$ Harland

N Unwin

W Watson

K G M M Alberti

Department of

Epidemiology \& Public

Health, University of

Newcastle

N Unwin

R Bhopal

$M$ White

Human Diabetes and Metabolism Research Centre, University of Newcastle

J O Harland

$\mathrm{N}$ Unwin

W Watson

$M$ Laker

K G M M Alberti

Department of Clinical Biochemistry and Metabolic Medicine,

University of

Newcastle

M Laker

Correspondence tò: Ms J Harland, Department of Primary Health Care,

University of Newcastle, The

Medical School, Framlington

Place, Newcastle upon Tyne NE2 $4 \mathrm{HH}$.

Accepted for publication February 1997
Results-Altogether 183 and 197 Chinese, and 310 and 315 Europid men and women respectively were seen. Compared with Europid men, Chinese men had a lower mean total cholesterol concentration (5.1 versus $5.6 \mathrm{mmol} / 1, p<0.001$ ) and $L D L$ cholesterol (3.2 versus $3.6 \mathrm{mmol} / 1$, p<0.001); lower BMI values (23.8 versus $\left.26.1 \mathrm{~kg} / \mathrm{m}^{-2}, \mathrm{p}<0.001\right)$; and smoked less (23\% versus $35 \%, p<0.01)$ ). Compared with Europid women, Chinese women also had lower mean lipid levels (total cholesterol: 4.9 versus $5.4 \mathrm{mmol} / 1$ p<0.001, LDL cholesterol: 2.8 versus 3.1 mmol/1 $p<0.001)$; BMI values (23.5 versus $\left.26.1 \mathrm{~kg} / \mathrm{m}^{-2}, \mathbf{p}<0.001\right)$; and far fewer were smokers $(1.4 \%$ versus $33 \%, p<0.001)$. Chinese women, however, had higher mean systolic (121 versus $117 \mathrm{mmHg}, p>0.05$ ) and diastolic $(75$ versus $68 \mathrm{mmHg}$, $\mathbf{p}<0.001)$ blood pressures. The prevalence of coronary heart disease was significantly lower in Chinese than Europid men $(4.9 \%$ versus $16.6 \%, p<0.001)$ but not significantly different in women $(7.3 \%$ versus $11.1 \%, p=0.16$ ).

Conclusion-Strategies for UK Chinese are needed to maintain this favourable risk factor profile and prevent any potential increase in the risk of coronary heart disease associated with increasing acculturation.

(F Epidemiol Community Health 1997;51:636-642)
The prevalence of coronary heart disease (CHD) varies widely among Chinese populations in different countries. The prevalence in China, however, is among the lowest in the world. ${ }^{1}$ Average annual mortality rates for cardiovascular diseases in men in Beijing are one tenth of those in Scotland. ${ }^{2}$ Mortality rates for $\mathrm{CHD}$ in Hong Kong are lower than in Britain and the USA. ${ }^{3-5}$ Levels of classic risk factors for CHD are also very low in China ${ }^{1}$; with the exception of smoking in Chinese men which ranges from 50-60\%. ${ }^{167}$ Serum cholesterol levels in China are very low compared with other parts of the world. ${ }^{1}$ Even in Chinese patients with myocardial infarction, serum lipid concentrations tend to be lower than in western populations. ${ }^{89}$

There is growing evidence, however, that the prevalence of CHD is increasing in China, Hong Kong, and Taiwan. ${ }^{40-12}$ Risk factors for $\mathrm{CHD}$ are also increasing in China in both rural and urban areas. ${ }^{10}$ In Hong Kong, CHD is the second major cause of death (after all cancers combined) and although age specific mortality rates for CHD appear to have levelled off in the past 10 years, there is no sign of any decrease in the prevalence of CHD in contrast with many western countries. ${ }^{13}$ Mortality rates for CHD in Hong Kong are higher in the more affluent socioeconomic groups, ${ }^{51314}$ as observed in Britain before the $1950 \mathrm{ss}^{15}$

There is evidence that migrant Chinese populations experience an increased risk of CHD. Chinese in Singapore have higher levels of CHD than Chinese in China and higher prevalences of hypertension and hypercholesterolaemia. ${ }^{16} \mathrm{Li}$ et $a l^{17}$ found that the prevalence of CHD in the Mauritius Chinese was $19.1 \%$ in men and $34.5 \%$ in women-five times higher than in Beijing using the same criteria.

Little is known about rates of CHD in Chinese populations in Europe. Although there were well over 100000 Chinese in the United Kingdom in 1991, comparatively little is known about their health and health needs. The aim of this population based survey was to compare the prevalence of CHD and risk factors in Chinese and Europid adults in Newcastle.

\section{Methods}

DEFINITION OF CHINESE AND EUROPID

For the purposes of the survey, Chinese refers to residents of the UK who on the basis of name, self definition, and appearance have 
ancestral origins in China, and includes those born in this country and migrating via other places. Europid refers to people whose ancestry lies in the European continent. The pragmatic nature of these terms is acknowledged.

THE CHINESE POPULATION IN NEWCASTLE

Before the second world war there were very few Chinese in Newcastle. The first few Chinese restaurants opened in Newcastle in the late 1940 s and early 1950 s, and by 1960 there were 30 restaurants in the area. ${ }^{18}$ The 1991 census identified 1114 Chinese in Newcastle. ${ }^{19}$ Of these, $65 \%$ were born in South East Asia (Hong Kong, Malaysia, and Singapore), $17 \%$ in mainland China, and $10 \%$ in the United Kingdom, with the rest being born in other parts of the world including Vietnam and the Caribbean. Seventy three per cent of the total UK Chinese population who were born in South East Asia were born in Hong Kong. ${ }^{20}$ Of the total Chinese population of the UK aged over 30 years, just under $4 \%$ were born in the $\mathrm{UK}^{20}$

IDENTIFICATION AND RECRUITMENT OF SUBJECTS The methods of identification and recruitment of subjects have been described in detail in a previous publication. ${ }^{21}$ In brief, these were as follows:

\section{Chinese adults}

All Chinese aged 25-64 years and normally resident in Newcastle upon Tyne were eligible to participate in the survey. The sample was initially identified using a name analysis ${ }^{22}{ }^{23}$ of the family health services authority (FHSA) register. Students in halls of residence were excluded because most Chinese students in Newcastle were from overseas and not normally resident in Newcastle. The amended lists were sent to GPs for checking against practice age-sex registers.

In addition, because we aimed to recruit all Chinese adults in Newcastle, the survey was widely publicised throughout the Chinese community through radio, television, newspapers (English language and Chinese), and posters. The Chinese Health Link worker, the main Chinese community organisations, and others working with the Chinese community were all informed of the survey and asked to encourage participation. Chinese subjects were recruited and screened between June 1991 and March 1993. Subjects identified from the FHSA register were sent a letter giving information about the project, followed by a letter with an appointment for screening. Nonresponders were sent a reminder letter and, if they did not make contact, were followed up by telephone or by home visiting on up to three occasions.

Subjects who were not on the FHSA register and who responded directly to the publicity aimed at the Chinese community made appointments for screening either by telephone, or via the Chinese Health Link Worker, the Chinese project worker, or relatives or friends who attended.

\section{KEY POINTS}

- This is the first population based survey of coronary heart disease and associated risk factors in a UK Chinese population.

- Levels of coronary heart disease and associated risk factors are currently low in UK Chinese.

- Chinese in China and elsewhere are experiencing an increase in coronary heart disease and associated risk factors.

- Increasing risk of coronary heart disease in the Chinese migrant populations has been associated with increasing acculturation.

- Health promotion strategies for UK Chinese are needed to maintain their currently favourable risk factor profile and prevent any potential increase in the risk of coronary heart disease.

\section{Europid adults}

In the postal questionnaire based Newcastle Health and Lifestyle Survey, ${ }^{24}$ every 30th person on the Newcastle FHSA register aged between 16 and 74 years was chosen (representing 6448 adults). Men and women aged over 25 years from this sample were used as the sampling frame for the present study. Any Chinese or South Asian sounding names were removed. The sampling frame was divided into 10 year age and sex bands, and the names within each band were randomly ordered. The first 180 names in each age and sex band formed the Europid sample.

Europid adults were recruited and screened between April 1993 and October 1994. Each subject was initially sent a letter informing them about the study, followed by an invitation to attend for screening. Up to three invitations were sent. Those with whom no contact was established after three invitations were sent a letter by recorded delivery mail.

\section{DATA COLLECTION}

All subjects attended the Clinical Research Centre at the Royal Victoria Infirmary in Newcastle between 0800 and 1000 hours after fasting from 2200 hours the night before.

\section{MEASUREMENT OF LIPIDS}

Lipids were measured on fasting blood samples. Cholesterol was estimated using a cholesterol oxidase/peroxidase method and calibrants traceable to the Centers for Disease Control definitive method. Triglycerides were estimated using a lipase/glycerol kinase method and HDL cholesterol was estimated by measuring the supernatant cholesterol concentration after precipitation of apolipoprotein B-containing lipoproteins with heparin and manganese. LDL cholesterol was calculated using the Friedewald formula. ${ }^{25}$ Apolipoproteins A-I and B were estimated by an immunoturbidometric method using a DPA analyser (Bayer).

Until May 1994 the lipid analyses were performed on a Cobas Bio centrifugal analyser (Roche Products Ltd, Welwyn Garden City, 
UK) and after this date a DAX analyser was used (Bayer plc, Basingstoke, UK). The relationship between results for the two analysers are shown by the following equations where $\mathrm{x}=$ Cobas Bio and $\mathrm{y}=\mathrm{DAX}$ results. Cholesterol, $\mathrm{y}=1.02 \mathrm{x}-0.08(\mathrm{r}=0.994)$;

HDL cholesterol, $\mathrm{y}=1.04 \mathrm{x}+0,(\mathrm{r}=0.987)$;

Triglycerides, $\mathrm{y}=1.11 \mathrm{x}-0.02(\mathrm{r}=0.998)$.

The regression equations for the relationships between the two methods of lipid analysis were derived from analysing 46 clinical samples by both methods during a period of one week. Throughout the whole period the laboratory participated in an external quality assurance scheme which showed no changes in bias (inaccuracy) for cholesterol or HDL cholesterol during the study. The data for triglycerides confirmed the positive bias of the DAX compared with the Cobas Bio data, and therefore results obtained with the DAX were adjusted according to the regression equation. No external quality assurance for apolipoproteins was available but internal quality assurance was used throughout the study and no changes in bias occurred.

PHYSICAL MEASUREMENTS AND ECG

Height was measured without shoes to the nearest $0.5 \mathrm{~cm}$ and weight was measured with the subject lightly clothed to the nearest $100 \mathrm{~g}$. Waist and hip circumference were measured to the nearest centimetre at the mid point between the lower costal margin and the superior iliac crest, over the greater trochanters of the hips with the subject standing. Waist circumference was measured with the waist unclothed and hip circumference over the subject's underwear.

Blood pressure and pulse were measured twice after the subject had been seated quietly for at least 20 minutes after any venepuncture. The reported results are the mean of two measurements. In the Chinese subjects, blood pressure and pulse were measured using a Takeda electronic machine and a $12.5 \times 23 \mathrm{~cm}$ cuff. In the Europid subjects, blood pressure and pulse were measured manually by observers trained to follow the method of the British Hypertension Society ${ }^{26}$ using a mercury sphygmomanometer and an alternate size cuff $(12.5 \times 35 \mathrm{~cm})$. A correction factor was applied to the blood pressure measurements taken with the Takeda automated machines to enable them to be compared with those made using the standard mercury sphygmomanometer in the Europids. Correction was done by applying a linear regression coefficient and constant to the systolic and diastolic Takeda readings respectively. These coefficients and constants were taken from a study conducted by ourselves comparing the Takeda with the standard mercury sphygmomanometer. This showed that on average the Takeda machines read $2.4 \mathrm{mmHg}$ lower on systolic readings and $2 \mathrm{mmHg}$ lower on diastolic readings. ${ }^{27} \mathrm{~A}$ 12-lead ECG was performed.

QUESTIONNAIRE

The questionnaire included the Rose questionnaire for angina and chest pain. ${ }^{28}$ The Chinese questionnaire was translated into written Chinese by the translation service at Newcastle City Council. It was partly completed by interview and partly self completed. The interview section was administered by a trained Chinese interviewer. Subjects who had difficulty with the self completion section were helped by the interviewer. The Europid questionnaire was entirely self completed. Those with literacy problems were helped by a trained interviewer. The questions used in the Chinese and Europid questionnaires were identical where appropriate.

ETHICS, FEEDBACK, AND INTERVENTION

The study was approved by the Newcastle upon Tyne Joint Ethics Committee and informed consent was obtained from all participants.

With their consent; subjects received the results of their cardiovascular screening and a copy of the results was sent to their general practitioner. Those with hypertension, hypercholesterolaemia, anaemia, and overweight/ obesity were advised to see their general practitioner. Chinese subjects were invited to discuss any queries about their results with the Chinese project worker or the Chinese Health Link Worker.

\section{DEFINITION OF RISK FACTORS AND CODING OF} ECG

Where appropriate, risk factors for $\mathrm{CHD}$ were defined in accordance with WHO criteria. ${ }^{29}$ Subjects were classified as hypertensive if their mean systolic blood pressure was $\geqslant 160 \mathrm{mmHg}$ or mean diastolic blood pressure was $\geqslant 95$ $\mathrm{mmHg}$. Subjects who were currently taking medication for hypertension were classified as hypertensive. Cut off points of $\geqslant 6.5 \mathrm{mmol} / 1$ and $\geqslant 7.8 \mathrm{mmol} / 1$ were used to define hypercholesterolaemia in men and women respectively. ${ }^{25}$ Hypertriglyceridaemia was defined as serum triglyceride $\geqslant 2.3 \mathrm{mmol} / \mathrm{l}^{25}$ Total cholesterol to HDL cholesterol ratios were calculated and a ratio of greater than 5 was considered high. ${ }^{25}$ Body mass index (BMI) was calculated as weight in $\mathrm{kg}$ divided by height in $\mathrm{m}^{2}$. Subjects were classified as overweight if their BMI was $\geqslant 25$ for women and $\geqslant 27$ for men, and obese if the BMI was $\geqslant 30$ in either sex. $^{30}$

ECGs were Minnesota $\operatorname{coded}^{31}$ by two trained and independent coders and those with discrepant reports were passed to a third independent coder. Probable CHD was defined as Minnesota coding 1.1-1.2 (large $\mathrm{Q}$ and $\mathrm{QS}$ ); and possible $\mathrm{CHD}$ as Minnesota coding 1.3 (small Q and QS), or 4.1-4.4 (ST-T depression), or 5.1-5.3 ( $\mathrm{T}$ wave inversion and flat), or 7-1-1 (complete left bundle branch block). ${ }^{31}$

Angina and previous possible myocardial infarction were defined from answers to the Rose questionnaire. ${ }^{28}$ Subjects with either a positive ECG result, or angina, or previous myocardial infarct from the questionnaire were classified as having suspected CHD. ${ }^{28}$ 
Table 1 Cardiovascular risk factors (mean (SD)) for Europid and Chinese men and women aged 25 to 64 years (age adjusted to the 1991 England and Wales population)

\begin{tabular}{|c|c|c|c|c|c|c|}
\hline \multirow[b]{2}{*}{ Risk factors } & \multicolumn{3}{|l|}{ Men } & \multicolumn{3}{|l|}{ Women } \\
\hline & Europid & Chinese & Difference $(95 \% C I)$ & Europid & Chinese & Difference $(95 \%$ CI) \\
\hline No & 310 & 183 & & 315 & 197 & \\
\hline Total cholesterol (mmol/l) & $5.6(1.1)$ & $5.1(1.0)$ & $0.5(0.3,0.7)^{\star \star \star}$ & $5.4(1.2)$ & $4.9(1.0)$ & $0.5(0.3,0.7)^{\star \star \star}$ \\
\hline HDL cholesterol & $1.3(0.4)$ & $1.4(0.4)$ & $-0.1(-0.135,0.003)$ & $1.6(0.4)$ & $1.6(0.4)$ & $0(-11,0.03)$ \\
\hline ApoA $(\mathrm{mmol} / \mathrm{l})$ & $1.5(0.3)$ & $1.2(0.3)$ & $0.3(0.28,0.38)^{\star \star \star}$ & $1.7(0.3)$ & $1.2(0.3)$ & $0.5(0.42,0.52)^{\star \star \star}$ \\
\hline LDL cholesterol $(\mathrm{mmol} / \mathrm{l})$ & $3.6(0.9)$ & $3.2(0.9)$ & $0.4(0.2,0.6)^{\star \star \star}$ & $3.1(1.0)$ & $2.8(0.9)$ & $0.3(0.17,0.51)^{\star \star \star}$ \\
\hline ApoB $(\mathrm{mmol} / \mathrm{l})$ & $1.0(0.3)$ & $0.7(0.2)$ & $0.3(0.2,0.3)^{\star \star \star}$ & $0.9(0.3)$ & $0.7(0.2)$ & $0.2(0.19,0.28)^{\star \star \star}$ \\
\hline Triglycerides $(\mathrm{mmol} / \mathrm{l}) \dagger$ & $1.4(0.9-2.0)$ & $1.0(0.7-1.5)$ & $0.4^{\star \star \star}$ & $1.2(0.8-1.8)$ & $0.8(0.6-1.2)$ & $0.4^{\star \star \star}$ \\
\hline Systolic BP (mmHg) & $126(17)$ & $123(15)$ & $3(0.2,6)^{\star}$ & $117(18)$ & $121(19)$ & $-4(-7,-1)^{\star}$ \\
\hline Diastolic BP (mm/Hg) & 78 (11) & $77(10)$ & $1(-1,3)$ & $68(10)$ & $75(11)$ & $-7(-9,-5)^{\star \star \star}$ \\
\hline Resting pulse (per minute) & $70(11)$ & $70(9)$ & $0(-2,2)$ & $75(10)$ & $76(11)$ & $-1(-3,1)$ \\
\hline Height $(\mathrm{cm})$ & $174(10)$ & $166(6)$ & $8(6,10)^{\star \star \star}$ & $161(7)$ & $155(5)$ & $7(5,8)^{\star \star \star}$ \\
\hline Weight (kg) & 79 (14) & $66(10)$ & $13(11,16)^{\star \star \star}$ & $68(13)$ & $56(8)$ & $11(9,13)^{\star \star \star}$ \\
\hline $\mathrm{BMI}\left(\mathrm{kg} / \mathrm{m}^{2}\right)$ & $26.1(4.1)$ & $23.8(3.2)$ & $2.3(1.7,3.0)^{\star \star \star}$ & $26.1(4.1)$ & $23.5(3.2)$ & $2.6(1.8,3.3)^{\star \star \star}$ \\
\hline Waist $(\mathrm{cm})$ & 91 (11) & $83(8)$ & $8(6,9)^{\star \star \star}$ & $79(12)$ & $77(9)$ & $2(0.1,4)^{\star}$ \\
\hline Hip (cm) & $100(7)$ & $93(8)$ & $7(6,9)^{\star \star \star}$ & $101(9)$ & $92(8)$ & $9(8,11)^{\star \star \star}$ \\
\hline Waist/hip ratio & $0.90(0.07)$ & $0.89(0.05)$ & $0.01(0.002,0.023)^{\star}$ & $0.78(0.06)$ & $0.84(0.06)$ & $-0.06(-0.07,-0.05)^{\star \star \star}$ \\
\hline
\end{tabular}

† Median (interquartile range)

p values: ${ }^{\star}<0.05-0.01, \star \star<0.01-0.001, \star \star \star<0.001$

$\mathrm{Apo}=$ apolipoprotein, $\mathrm{BP}=$ blood pressure, $\mathrm{BMI}=$ body mass index, $\mathrm{LDL}=$ low density lipoprotein, $\mathrm{HDL}=$ high density lipoprotein

DATA ANALYSIS

The data were coded, double entered on computer to check for errors, and analysed using the Statistical Package for Social Sciences (SPSS).$^{32}$ All variables compared between the Chinese and Europids were examined initially by 10 year age groups. Because there was no systematic difference by age group only age adjusted comparisons are presented. (Tables of the variables by 10 year age group are available from the authors). Figures were directly age standardised (using the 1991 England and Wales population as standard) by applying weights within SPSS such that the age structures of the study populations were the same as the standard population but the overall size of each study population was unaffected. ${ }^{32}$ Confidence intervals on proportions and the differences between proportions were calculated using the computer programme Confidence Interval Analysis (BMJ, 1991). The distribution of all variables except triglycerides closely approximated to a normal distribution, and differences between Chinese and Europid men and women for these continuous variables were assessed using the independent samples $t$ test. Data on triglycerides are presented using medians and inter quartile range, and differences were assessed using the Mann-Witney $U$ test.

Logistic regression analysis was carried out in SPSS with CHD as the dependent variable and ethnicity as an independent variable. Risk factors were sequentially entered to determine if differences in the prevalence of CHD between Chinese and Europids were "explained" by differences in risk factor levels. Odds ratios are presented with $95 \%$ confidence intervals.

\section{Results}

RESPONSE

The FHSA register for Newcastle yielded 1702 individuals with Chinese sounding names, from which 638 students living in halls of residence were excluded. Of the remaining 1064 individuals, 658 were no longer resident at the address given on the FHSA register, 21 were not Chinese, and no contact was established with 18 individuals. Of the 367 Chinese adults identified, 217 took part in the survey, giving a participation rate for subjects recruited from the FHSA register of $59 \%$ ( $54 \%$ for men and $64 \%$ for women). Respondents and non respondents from the FHSA register did not differ with respect to age and male:female ratio, the only variables for which we had information on non-respondents. A further 163 individuals, who were not on the FHSA register but who satisfied our entry criteria, came forward in response to the publicity campaign and took part, giving a final study sample of 380 Chinese subjects (183 men and 197 women). There were no statistically significant differences in age, male:female ratio, marital status, socio-economic status, educational level, and smoking status between FHSA and non-FHSA respondents. Mean levels of total serum cholesterol, systolic and diastolic blood pressure, BMI and waist/hip ratio were similar in both groups. The overall likely response in the Chinese is addressed in the discussion.

A total of 1260 invitations were sent to Europid population men and women aged 25-64 years. Three hundred and twenty six people were no longer resident at the address given on the FHSA register. Thus, 944 individuals (444 men and 500 women) received an invitation, and 625 (66.2\%) Europid adults attended for screening: 310 men (response rate $69.8 \%$ ) and 315 women (response rate $63.0 \%$ ).

PREVALENCE OF CHD AND RISK FACTORS

Table 1 shows that Chinese of both sexes had a favourable lipid profile compared to the Europid men and women. Mean levels of total cholesterol, apolipoprotein A, LDL cholesterol, apolipoprotein $\mathrm{B}$, and triglycerides were significantly lower in Chinese men compared with Europid men, and Chinese women compared with Europid women. The exception was HDL cholesterol which was not significantly different in the two ethnic groups.

Systolic and diastolic blood pressure were similar in Chinese men and Europid men. 
Table 2 The prevalence (\%) of coronary heart disease risk factors in Europid and Chinese men and women aged 25 to 64 years (age adjusted to the 1991
England and Wales population) England and Wales population)

\begin{tabular}{|c|c|c|c|c|c|c|}
\hline \multirow[b]{2}{*}{ Risk factors } & \multicolumn{3}{|l|}{ Men } & \multicolumn{3}{|l|}{ Women } \\
\hline & Europid & Chinese & Difference (95\% CI) & Europid & Chinese & Difference $(95 \%$ CI) \\
\hline No & 310 & 183 & & 315 & 197 & \\
\hline Cholesterol $>6.5 \mathrm{mmol} / 1$ & 21.9 & 9.3 & $12.6(6.5,19.0)^{\star \star \star}$ & 16.9 & 5.4 & $11.5(6.0,16.5)^{\star \star \star}$ \\
\hline Cholesterol $>7.8 \mathrm{mmol} / \mathrm{l}$ & 3.4 & 1.0 & $2.4(-0.09,5.0)$ & 4.1 & 2.2 & $1.9(-0.9,5.1)$ \\
\hline Total cholesterol/HDL ratio $>5$ & 33.7 & 18.6 & $15.1(7.3,22.9)^{\star \star \star}$ & 11.0 & 5.7 & $5.3(0.5,10.2)^{\star}$ \\
\hline Triglycerides $\geqslant 2.3 \mathrm{mmol} / \mathrm{l}$ & 19.7 & 7.0 & $12.7(6.8,18.4)^{\star \star \star}$ & 14.0 & 6.4 & $7.6(2.5,12.7)^{\star}$ \\
\hline $\mathrm{BP}>160 \mathrm{mmHg}$ systolic or $\geqslant 95$ diastolic & 10.3 & 7.9 & $2.4(-3.1,7.4)$ & 3.3 & 7.8 & $-4.5(-8.6,-0.3)^{\star}$ \\
\hline On medication for hypertension & 6.9 & 4.0 & $2.9(-1.0,6.9)$ & 5.6 & 7.3 & $-1.7(-6.6,2.7)$ \\
\hline Hypertension (raised BP or on medication & 14.9 & 10.2 & $4.7(-1.5,10.4)$ & 7.2 & 12.1 & $-4.9(-10.3,0.05)$ \\
\hline Overweight (BMI $\geqslant 27$ men, $\geqslant 25$ women) & 35.7 & 17.1 & $18.6(10.9,26.3)^{\star \star \star}$ & 51.4 & 31.3 & $20.1(11.6,28.6)^{\star \star \star}$ \\
\hline Obese $(\mathrm{BMI} \geqslant 30)$ & 14.5 & 4.5 & $10(5.2,15.1)$ & 15.8 & 2.1 & $13.7(9.3,18.4)^{\star \star \star}$ \\
\hline Current smoker & 34.8 & 22.9 & $11.9(3.8,20.0)^{\star \star}$ & 32.6 & 1.4 & $31.2(25.7,36.6)^{\star \star \star}$ \\
\hline
\end{tabular}

Table 3 The prevalence (\%) of coronary heart disease (CHD), based on questionnaire and Electrocardiogram (ECG), in Europid and Chinese men and women aged 25 to 64 years (age adjusted to the 1991 England and Wales population)

\begin{tabular}{|c|c|c|c|c|c|c|}
\hline \multirow[b]{2}{*}{ Risk factors } & \multicolumn{3}{|l|}{ Men } & \multicolumn{3}{|l|}{ Women } \\
\hline & Europid & Chinese & Difference $(95 \%$ CI) & Europid & Chinese & Difference $(95 \% C I)$ \\
\hline No & 310 & 183 & & 315 & 197 & \\
\hline \multicolumn{7}{|l|}{ On basis of Rose questionnaire: } \\
\hline $\begin{array}{l}\text { Angina } \\
\text { Possible MI }\end{array}$ & 8.4 & 3.2 & $5.2(1.1,9.1)^{\star}$ & 6.7 & 4.1 & $2.6(-1.3,6.5)$ \\
\hline \multirow{2}{*}{\multicolumn{7}{|c|}{ On basis of resting ECG: }} \\
\hline & & & & & & \\
\hline Probable CHD & $\begin{array}{l}6.7 \\
1.6\end{array}$ & $\begin{array}{l}5.5 \\
0.5\end{array}$ & $\begin{array}{l}1.2(-3.1,5.7) \\
1.1(-0.7,5.7)\end{array}$ & $\begin{array}{l}10.1 \\
0.5\end{array}$ & $\begin{array}{l}17.2 \\
0\end{array}$ & $\begin{array}{l}-7.1(-13.5,-0.9)^{\star} \\
0.5(-0.2,1.7)\end{array}$ \\
\hline \multicolumn{7}{|l|}{ Rose questionnaire and ECG: } \\
\hline Questionnaire and probable CHD on ECG & 16.6 & 4.9 & $11.7(6.4,16.7)^{\star \star \star}$ & 11.1 & 7.3 & $3.8(-1.7,8.7)$ \\
\hline Questionnaire and all CHD on ECG & 20.2 & 9.2 & $11.0(4.9,17.2)^{\star \star \star}$ & 19.6 & 19.5 & $0.1(-6.7,7.4)$ \\
\hline
\end{tabular}

p values: ${ }^{\star}<0.05-0.01,{ }^{\star \star}<0.01-0.001,{ }^{\star \star \star}<0.001$

Chinese women had significantly higher mean systolic and diastolic blood pressure than Europid women. Resting pulse was similar in Chinese and Europid men, and in Chinese and Europid women.

Chinese men were significantly shorter and lighter than Europid men. They had lower mean BMI, and narrower waist and hip measurements. The mean waist hip ratio was similar in men in both ethnic groups. Chinese women were also significantly shorter and lighter than their Europid counterparts with lower mean BMI and significantly narrower hips and waists. Interestingly, however, Chinese women had a significantly higher waist hip ratio than Europid women.

The prevalences of hypercholesterolaemia and hypertriglyceridaemia were lower in Chinese than Europids in both men and women (table 2). This difference was statistically significant for hypercholesterolaemia $\geqslant 6.5 \mathrm{mmol} / \mathrm{l}$, hypertriglyceridaemia and the total cholesterol:HDL ratio in both men and women. The prevalence of hypertension was not significantly different between Chinese and Europid men. In women the prevalence of hypertension was significantly higher in the Chinese

Chinese men and women were half as likely to be overweight than their Europid counterparts ( $p<0.001$ in both sexes). Three times as many Europid men, and seven times as many Europid women were obese as Chinese men and women respectively $(\mathrm{p}<0.0001)$. Chinese men and women were less likely to be current smokers than Europid men and women. This was especially true of Chinese women, only $1.4 \%$ of whom were current smokers. The prevalence of $\mathrm{CHD}$ in Chinese men and women was lower than in Europid men and women (table 3). The prevalences of angina and possible previous myocardial infarct (Rose questionnaire), and probable CHD (major ECG abnormalities) were low in the Chinese in both sexes. Chinese men had lower levels of angina, possible myocardial infarction, and ECG abnormalities than Europid men. When data from the Rose angina questionnaire and ECG results were combined, Chinese men had a significantly lower level of CHD than Europid men.

The prevalence of possible myocardial infarction was lower in Chinese women compared with Europid women. The prevalence of possible CHD was significantly higher in Chinese women than Europid women due to the higher prevalence of ST-T wave abnormalities in the former. When the Rose angina questionnaire data were combined with data on major ECG abnormalities, the prevalence of CHD was not significantly different between Chinese women and Europid women. When minor ECG abnormalities were included in the definition, the prevalence of CHD in Chinese and Europid women was similar.

Logistic regression analysis was carried out to determine if differences between Chinese and Europids in the prevalence of CHD (based on the Rose questionnaire and major ECG abnormalities) were explained by differences in the risk factors. In fact controlling for the risk factors made little difference whether taking the men as group or the men and women together. For example, taking men and women together and controlling for age and sex the odds ratio for CHD (Europid versus Chinese) 
was 2.46 (95\% CI 1.48, 4.10, p<0.001). With the addition of LDL cholesterol, triglycerides, and current smoking status the OR was 2.27 $(1.34,3.86, \mathrm{p}=0.0024)$; and with the addition of systolic and diastolic blood pressure and BMI and waist hip ratio it was $2.16(1.22,3.83$, $\mathrm{p}=0.0085$ ).

\section{Discussion}

This is the first population based study of CHD in a Chinese population in Europe. The paucity of information on the health and health needs of Chinese populations in the UK has been noted and research on this group has been identified as a priority. ${ }^{33}$ This lack of research is at least partly explained by the difficulties in accessing study populations. We have discussed previously the strengths and weaknesses of our strategy for recruiting Chinese subjects. ${ }^{21}$ Suffice to note here that in the absence of an accurate sampling frame we can only provide an estimate of the response rate which is based on comparison to 1991 census figures. We estimate that between 60 and $70 \%$ of the target population were screened. In the Europid population we screened $66 \%$ of those who received an invitation. These response rates are similar to those in several studies comparing the prevalence of CHD in Europid and South Asian populations in the $\mathrm{UK}^{35}{ }^{36}$

There were some differences in the methods used to collect the data in the Chinese and Europid surveys. In addition, the surveys took place at different points in time which raises the possibility of laboratory drift and changes in observer error. Ideally for the comparisons made here the surveys would have been conducted at the same time using the same methods. We have attempted to address these issues in a number of ways. For the measurement of lipids internal and external quality control checks were applied throughout the study period. These are detailed in the methods section and when the lipid analyser changed it was possible to correct for the small differences between the two analysers. In the case of blood pressure measurement, we undertook our own study to compare the automated Takeda machines with the standard mercury sphygmomanometer. ${ }^{27}$ For the measurement of anthropometric variables, we used the same protocols and undertook regular retraining sessions for all observers throughout the period of the study. Finally, the Rose angina questionnaire was completed by interview in the Chinese survey and by self completion in the Europid survey. We have been unable to find any published information comparing interview with self administration of the Rose angina questionnaire. We note that the questionnaire was originally designed for administration by interview but that Rose and colleagues also indicated that "with slight modifications it is suitable for selfadministration in literate populations." 28

In comparing risk factor levels, the caveat must be applied that the risk conferred by a certain level may differ between ethnic groups. This caveat is particularly important in the interpretation of the comparisons made in table 2, which are based on cut off points for the different factors. The cut off points may not have the same significance in both groups (we have presented them because such cut off points are widely used and provide a readily accessible summary of the data). With this caveat in mind it appears that compared with the Europid population in Newcastle, the Newcastle Chinese have a low prevalence of CHD and a favourable risk factor profile. Both Chinese men and women had favourable lipid profiles, smoked less and had lower levels of obesity than the Europid men and women. However, mean systolic and diastolic blood pressure levels were higher in Chinese compared with Europid women. We undertook a logistic regression analysis to test the hypothesis that differences in prevalence of CHD between the Chinese and Europids are "explained" by differences in risk factor levels. Controlling for any of the aforementioned risk factors made little difference to the Europid to Chinese odds ratio. The interpretation of this is not clear cut. On the one hand it does not support the hypothesis that the lower prevalence of CHD is due to the lower levels of the aforementioned risk factors. On the other hand a cross sectional study design is a poor design for examining the relationship between putative modifiable risk factors and an outcome which may take decades to develop.

Although Chinese women had a significantly higher prevalence of suspected CHD (minor ECG abnormalities), this was primarily due to the higher prevalence of ST-T wave abnormalities in Chinese women compared with Europid women. However, minor ECG abnormalities have not been found to be associated with increased longterm risk of CHD in women and may be influenced by other factors. ${ }^{37}$ This high level of minor ECG abnormalities has been noted in other populations of Chinese women. ${ }^{17}$ Most Chinese in the UK are from Hong Kong (67\%) followed by Singapore and Malaysia and mainland China. ${ }^{20}$ Identifying an appropriate Chinese comparison population for the UK Chinese therefore is not easy. Published data on the prevalence of CHD and risk factors for CHD in Hong Kong tends not to be population based, but comes from various populations including self referred cholesterol screening programmes ${ }^{38}$ and work place based screening programmes. ${ }^{7}$

In the absence of population based data from Hong Kong we compared the Newcastle Chinese with the Chinese in Beijing, China, who were studied as part of the MONICA project $^{1}$ as this data is population based and was collected using a protocol similar to our own. Compared with Chinese in Beijing, the Newcastle Chinese appear to have higher cholesterol levels, but a lower prevalence of smoking and lower blood pressure levels.

Studies of Chinese populations in Singapore, Malaysia, USA, and Mauritius have demonstrated high levels of CHD and associated risk factors. ${ }^{16} 1739$ For example, Gerber and Madhaven ${ }^{40}$ found that Chinese in the USA had higher levels of mortality from CHD than Chinese in China, and that the risk of 
CHD increased with the length of residence in the USA. Chinese born in the USA were at higher risk than foreign born Chinese. ${ }^{40}$ In a study of Chinese in New York City's Chinatown, the serum cholesterol levels and prevalence of hypercholesterolaemia in the Chinese approached those in the Caucasian population. ${ }^{39}$ These facts suggest that lipid levels in the Newcastle Chinese may increase in future with increasing acculturation with an associated increase in the rate of CHD.

In conclusion, this first study of a Chinese population in Europe has shown a low level of CHD risk factors in comparison with the local indigenous Europid population. Assuming that this risk factor profile is also found in other Chinese populations in the UK, we suggest that it would be appropriate to develop coronary prevention strategies now to maintain this favourable profile, and to prevent the likely increase in CHD rates with increasing acculturation.

We thank Jennifer Yuen, Hong Seng Chin, Sui Lin Cheung, Francis Liu, Alice Tang, Eddie Tang, Peter Chen, Sow Fong Cole, the North East Chinese Association, the Wah Sen Sah, members of the Community Relations Council and all members of the Chinese community who supported the project. Sisters of the Chinese community who supported the project. Sisters
Margaret Miller, Catherine Turner and Mavis Brown, and nurse Margaret Miller, Catherine Turner and Mavis Brown, and nurse Amanda McEwan helped to run the screening sessions; they were assisted at times by Drs Ayesha Motala, Kaushik Ramaiya, and Dilip Singh. Mr Christopher Foy provided statistical advice. Nigel Unwin was supported by a grant from the Barclay Trust.
Newcastle upon Tyne Health Authority, the Barclay Trust and Newcastle upon Tyne Health Authority, the Barclay Trust and
the British Diabetic Association are thanked for financial support.

Funding: Nigel Unwin was supported by a grant from the Barclay Trust. Newcastle upon Tyne Health Authority, the Barclay Trust, and the British Diabetic Association also provided financialsupport.

Conflicts of interest: none.

1 WHO MONICA Project. Geographical variation in the major risk factors of coronary heart disease in men and women aged 35-64 years. World Health Stat $Q$ 1988;41:115 38.

2 Tunstall-Pedoe H, Smith W, Taverdale R. How-often-thathigh graphs of serum cholesterol: findings from the Scottish Heart Health and Scottish MONICA studies. Lancet 1988; i:540-2.

3 Woo K, Wallance-Owen J. Changing prevalence and pattern of cardiovascular diseases in Hong Kong: A perspective in the 1990s. Chin Med f (Engl) 1988;101:579-86.

4 Woo K, Donnan S. Epidemiology of coronary arterial Woo K, Donnan S. Epidemiology of coronary

5 Donnan SP, Ho SC, Woo J, et al. Risk factors for acute myocardial infarction in a southern Chinese population. Ann cardial infarction in a so

6 Tomson D, Coulter A. The bamboo smoke screen: Tobacco smoking in China. Health Promotion 1987;2:95-108.

7 Siegrist J, Bernhardt R, Feng Z, Schettler G. Socioeconomic differences in cardiovascular risk factors in China. Int $\mathscr{f}$ Epidemiol 1990;19:905-10

8 Chen Z, Peto R, Collins R, MacMahon S, Lu J, Li W. Serum cholesterol concentration and coronary heart disease in population with low cholesterol concentrations. $B M \mathcal{I}$ 1991;303:276-82

9 Schwartzkoff W, Schleicher J, Pottins I, Yu S, Han C, Du D. Lipids, lipoproteins, apolipoproteins, and other risk factors in Chinese men and women with and without myocardial infarction. Atherosclerosis 1990;82:253-9.

10 Zhai S, McGarvey S. Temporal changes and rural-urban differences in cardiovascular disease risk factors and mortality in China. Hum Biol 1992;64:807-19.

11 Woo K. Epidemiology of ischaemic heart disease and coronary risk factors in Hong Kong. Bulletin fournal of the Hong nary risk factors in Hong Kong. Bulletin
Kong Medical Association 1984;36:73-82.

12 Khoo KL, Tan H, Khoo TH. Cardiovascular mortality in peninsular Malaysia: 1950-1989. Med $\mathcal{f}$ Malaysia 1991;46: 7-20.
13 Lam Y, Lau E, Donnan S. Geographical and socioeconomic variations in ischaemic heart disease in men in Hong Kong. Ann Acad Med 1984;13:211-15.

14 Woo J, Ho SC, Wong SL, Tse CY, Chan KK, Kay CS, et al. Lipids, lipoproteins and other coronary risk factors in Chinese male survivors of myocardial infarction. Int $\mathcal{f}$ Cardiol 1993;39:195-202.

15 Marmot M, Adelstein A, Robinson N, Rose G. Changing social class distribution of heart disease. BMF 1978;2: 1109-12.

16 Hughes $\mathrm{K}$, Yeo P, Lun K, et al. Ischaemic heart disease and its risk factors in Singapore in comparison with othe countries. Ann Acad Med (Singapore) 1989;18:245-49.

$17 \mathrm{Li} \mathrm{N}$, Tuomilehto J, Dowse G, et al. Electrocardiographic abnormalities and associated factors in Chinese living in Beijing and in Mauritius. BMF 1992;304:1596-601.

18 Qiao L, Gopal K, Lo Hu P. Building bridges: forty years of the Chinese in Newcastle. SiYu 1989.

19 Office of Population Censuses and Surveys. 1991 census, county report: Tyne and Wear. London: HMSO, 1992.

20 Office of Population Censuses and Surveys and The General Register Office for Scotland. 1991 census: ethnic group and country of birth Great Britain. London: HMSO, group

21 Unwin N, Harland J, White M, et al. Body mass index, waist circumference, waist hip ratio and glucose intolerance in Chinese and Europid adults in Newcastle. $\mathcal{F}$ Epidemiol Community Health 1997;51:160-6.

22 Nicoll A, Bassett K, Ulijaszek S. What's in a name? Accuracy of using surnames and forenames in ascribing Asian ethnic identity in English populations. $\mathcal{f}$ Epidemio Community Health 1986;40:364-8.

23 Coldman A, Braun T, Gallagher R. The classification of ethnic status using name information. $\mathcal{f}$ Epidemiol Community Health 1986;42:390-5.

24 Harrington B, White M, Foy C, Raybould S, Harland J. The Newcastle health and lifestyle survey 1991: health and lifestyles in Newcastle. Newcastle: Newcastle Health Authority and Department of Epidemiology and Public Health, UniverDepartment of Epidemi
sity of Newcastle, 1993.

25 Betteridge DJ, Dodson PM, Durrington PN, et al. Management of hyperlipidaemia: guidelines of the British Hyperlipidaemia Association. Postgrad Med $\mathcal{F}$ 1993;69:359-69.

26 Petrie JC, O’Brien ET, Littler WA, deSwiet M, Padfield PL Dillon MJ. Recommendations on blood pressure measurement. London: British Medical Journal Publications, 1990.

27 Cartwright C, Unwin NC, Stephenson P. The agreement between the Takeda UA-731 automatic blood pressure measuring device and the manual mercury sphygmomanometer: an assessment under field conditions in Newcastle-upon-Tyne, UK. $\mathcal{F}$ Epidemiol Community Health 1996;50:218-22.

28 Rose G, Blackburn A, Gillum R, Prineas R. Cardiovascular survey methods. 2nd ed. Geneva: WHO, 1982.

29 WHO MONICA Project. WHO MONICA project: risk factors. Int 7 Epidemiol 1989;18:s46-s55.

30 Bennett P. Recommendations on the standardisation of methods and reporting of tests for diabetes and its microvascular complications in epidemiologic studies. Diabetes Care 1979;2:98-104.

31 Prineas R, Crow R, Blackburn H. The Minnesota code manual of electrocardiographic findings. London: John Wright, 1982

32 Norusis MJ, SPSS Inc. SPSS/PC+ 4.0 base manual. Chicago: SPSS Inc, 1990

33 Smaje C. Health, 'race' and ethnicity: making sense of the evidence. London: Kings Fund, 1995.

34 Home Affairs Committee. The Chinese community in Britain Second report from the Home Affairs Committee Session 198485. London: HMSO, 1985

35 McKeigue PM, Bela Shah, Marmot MG. Relation of central obesity and insulin resistance with high diabetes prevalence and cardiovascular risk in South Asians. Lancet 1991;337: 382-6.

36 McKeigue PM, Marmot MG, Syndercombe-Court YD, Cottier DE, Suraiya Rahman, Riemersma RA. Diabetes, hyperinsulinaemia and coronary risk factors in Bangladeshis in East London. Br Heart $\mathcal{f}$ 1988;60:390-6.

37 Lian YL, Liu K, Dyer A, et al. Sex differential in the relationship of electrocardiographic ST-T abnormalities to risk of coronary death: 11.5 year follow-up findings of the Chicago Heart Association detection project in Industry. Circulation 1987;72:347-52.

38 Fong PC, Tam SC, Tai YT, Lau CP, Lee J, Sha YY. Serum lipid and apolipoprotein distributions in Hong Kong Chinese. $\mathcal{F}$ Epidemiol Community Health 1994;48:355-9.

39 Pinnelas D, De La Torre T, Pugh J, Strand C, Horowitz S. Total serum cholesterol levels in Asians living in New York City: results of a self-referred cholesterol screening. NY State $f$ Med 1992:245-8.

40 Gerber L, Madhavan S. Epidemiology of coronary heart disease in migrant Chinese populations. Med Anthropol 1980;4:307-20. 